\title{
ANALISA FAKTOR-FAKTOR KENDALA KETERCAPAIAN SMART MOBILITY DALAM UPAYA MENUJU KONSEP SMART CITY (STUDI PADA KOTA TANGERANG SELATAN)
}

\author{
Gunartin*) \\ Email : dosen01339@unpam.ac.id
}

\begin{abstract}
ABSTRAK
ANALISA FAKTOR-FAKTOR KENDALA KETERCAPAIAN SMART MOBILITY DALAM UPAYA MENUJU KONSEP SMART CITY (STUDI PADA KOTA TANGERANG SELATAN) FokUS permasalahan penelitian ini yaitu faktor apa saja yang menjadi kendala ketercapaian smart mobility dalam upaya menuju konsep smart city di Kota Tangerang Selatan. Adapun tujuan penelitian untuk menganalisa faktor-faktor yang menjadi kendala ketercapaian smart mobility dalam upaya menuju konsep smart city Kota Tangerang Selatan. Metode analisis data adalah mendeskripsikan teknik analisis apa yang digunakan oleh peneliti untuk menganalisa data yang telah dikumpulkan. Penelitian ini menggunakan metode analisa statistik deskriptif. Sumber data penelitian adalah studi literatur, observasi dan wawancara dengan teknik pengambilan sampel menggunakan purposive sampling. Lokasi penelitian di Kota Tangerang Selatan, Banten. Hasil penelitian diperoleh informasi bahwa faktor-faktor kendala ketercapaian smart mobility dalam upaya menuju konsep smart city di Kota Tangerang Selatan antara lain aspek: 1) Peraturan Pemerintah Daerah, belum keluarnya Peraturan Pemerintah yang menjadi payung induk program smart city sehingga pelaksanaannya belum optimal; 2) Sumber Daya Manusia, yaitu minimnya jumlah sumber daya manusia yang latar belakang pendidikannya berbasis IT yang siap menjalankan program smart city; 3) Anggaran, hal ini karena sifatnya sentralisasi dan terkait birokrasi sehingga membutuhkan waktu untuk merealisasikan anggaran sementara permasalahan di lapangan membutuhkan penanganan yang cepat; dan 4) Kesadaran Masyarakat, bahwasanya kesadaran masyarakat mempunyai peran yang sangat besar dalam mewujudkan ketercapaian smart mobility menuju konsep smart city, karena program ini diperuntukkan masyarakat sehingga masyarakat harus mendukung ketercapaian program smart city secara optimal.
\end{abstract}

Kata kunci: smart city, smart mobility

\begin{abstract}
ANALYSIS OF SMART MOBILITY ACHIEVEMENT FACTORS IN EFFORTS TOWARDS THE SMART CITY CONCEPT (STUDY IN TANGERANG SELATAN CITY). The focus of this research problem is what factors are constraints to the achievement of smart mobility in an effort towards the smart city concept in South Tangerang City. The purpose of the study is to analyze the factors that are obstacles to the achievement of smart mobility in an effort towards the concept of the smart city of South Tangerang City. Data analysis method is to describe what analysis techniques are used by researchers to analyze the data that has been collected. This study uses descriptive statistical analysis methods. Sources of research data are literature studies, observations and interviews with sampling techniques using purposive sampling. Research location in South Tangerang City, Banten. The results of the study obtained information that the constraints of the achievement of smart mobility in the effort towards the concept of smart city in South Tangerang City were: 1) Regional Government Regulation, the Government Regulation regarding smart city programs has not yet been issued, so that the implementation has not been optimal; 2) Human Resources, lack of human resources with IT-based education background; 3) Budget, budget are usually centralized and related to bureaucracy so that it takes time to realize the budget while problems in the field require rapid handling; and 4) Public Awareness, public awareness has a very big role in realizing the achievement of smart mobility towards the concept of smart city, because this program is intended for the community so that people must support the achievement of smart city programs optimally.
\end{abstract}

Keywords: smart city, smart mobility

*) Dosen Program Studi FK 


\section{JURNAL ILMIAH ILMU MANAJEMEN}

\section{PENDAHULUAN}

\section{A. Latar Belakang}

Smart mobility salah satu dari komponen smart city yang yang merupakan gerakan cerdas dalam penanganan permasalahan terkait pengelolaan lalu lintas yang berbasis information technology (IT) secara sustainable. Pemerintah Kota Tangerang Selatan berupaya dapat mengelola kotanya secara cerdas dalam konsep pembangunan berkelanjutan. Tetapi pada prinsipnya menjadikan kota cerdas tidak semudah membalikkan telapak tangan. Predikat kota urban menjadikan Kota Tangerang Selatan berkembang pesat, begitu juga dengan laju pertambahan penduduk. Banyak pendatang dari luar kota yang menjadikan Kota Tangerang tempat mengembangkan karir.

Efek laju pertumbuhan penduduk salah satunya volume kendaraan di Kota Tangerang Selatan terus meningkat. Meningkatnya jumlah penduduk berdampak pada semua sektor yaitu kemacetan lalu lintas, penumpukan sampah, polusi, dan penataan kota secara keseluruhan. Program smart city hadir untuk mengelola kota secara cerdas dengan basis IT dengan tujuan memberikan layanan informasi pada masyarakat secara mudah dan cepat sehingga permasalahan dapat segera ditangani.

Kota Tangerang Selatan telah mendapatkan statement sebagai kota cerdas pada tahun 2016, tetapi sampai sekarang predikat kota cerdas belum juga dicapai. Smart city merupakan sebuah proses konsep program berkelanjutan yang membutuhkan sinergisitas dari semua elemen masyarakat dan keenam komponennya. Belum tercapainya konsep smart city tentu banyak faktor yang menjadi kendala. Berdasarkan latar belakang tersebut peneliti tertarik untuk menganalisa faktor yang menjadikan kendala tercapainya konsep smart city dengan judul "Analisa Faktor-Faktor Kendala Ketercapaian Smart Mobility Dalam Upaya Menuju Konsep Smart City (Studi Pada Kota Tangerang Selatan)

\section{B. Fokus Penelitian}

Mengacu pada konteks penelitian di atas bahwa konsep smart city sudah dicanangkan pada tahun 2016 untuk Kota Tangerang Selatan tetapi hingga sekarang predikat kota cerdas belum tercapai. Fenomena ini yang membuat fokus peneliti untuk mengeksplorasi dan menganalisa fenomena tentang faktor-faktor apa yang menjadi kendala ketercapaian smart mobility dalam upaya menuju konsep smart city Kota Tangerang Selatan.

\section{Tujuan Penelitian}

Mengelola kota secara cerdas menjadi tujuan pemerintahan Kota Tangerang Selatan. Hal ini tentu membutuhkan waktu dan proses untuk dapat mewujudkannya. Meskipun pada tahun 2016 sudah dicanangkan sebagai kota cerdas namun waktu dua tahun belum cukup untuk mencapai predikat sebagai kota cerdas. Banyak faktor yang menjadi kendala ketercapaian smart city di Kota Tangerang Selatan. Untuk itu, tujuan dari penelitian ini adalah untuk menganalisa dan mendeskripsikan faktor-faktor yang menjadi kendala kercapaian konsep smart city Kota Tangerang Selatan

\section{Tinjauan Pustaka}

\section{A. Konsep Smart City}

Konsep smart city merupakan konsep kota berbasis pelayanan teknologi untuk mempercepat pembangunan daerah terutama dalam hal layanan publik. Konsep smart city juga merupakan konsepmengatasi kendala dengan menggunaakan teknologi untuk meningkatkan layanan publik. Layanan publik ini diatur dalam Undang-Undang No 25 Tahun 
2009 tentang pelayan publik. Pelaksanaan pelayanan publik ini diatur dalam Peraturan Pemerintah No 96 Tahun 2016.

Mengelola kota dengan konsep smart city telah diwacanakan oleh Kementrian Perencanaan Pembangunan Nasional dalam acara Konferensie-Indonesia Initiative (KII) dan Smart Indonesia Initiatives (SII) Forum ke-1 di Bandung pada 15 Oktober 2015 dengan topik "Pengembangan Kota Cerdas di Indonesia". Berdasarkan konferensi tersebut disajikan permasalahan dan tantangan perkotaan, meliputi:

1. Penentuan Standar Pelayanan Perkotaan;

2. Kualitas dan produktivitas sumber daya manusia;

3. Terbatasnya sumber pendanaan untuk pembiayaan pembangunan perkotaan;

4. Peraturan yang berorientasi kepada struktural;

5. Kualitas dan kapasistas sparatur pemerintah;

6. Rendahnya daya saing, produktivitas serta belum berkembangnya ekonomi lokal.

Konsep smart city juga tertuang pada Laporan Akhir Kajian Penilaian dan Penyusunan Blue Print Kota Tangerang Selatan. Dinyatakan bahwa mengelola kota untuk menjadi cerdas berkelanjutan merupakan kewajiban yang tidak dapat dibantah keberadaannya sesuai dengan kemampuannya dalam mengembangkan konsep kota cerdas yang meliputi: intelegent sity, green city, digital city, liveable city dan sustainable city. Hal ini didasarkan pada PP No 96 Tahun 2012 tentang Pelaksanaan Undang-undang No 25 Tahun 2009 tentang Pelayanan Publik.

Hal ini juga dikemukakan oleh Nurmandi (2014) bahwasannya kota cerdas mengacu kepada 3 unsur pentingyaitu faktor manusia, teknologi, dan kelembagaan.Menurutnya, unsur penting yang menjadiciri masyarakat kota cerdas adalah kepercayaan,norma, dan jaringan. Selain itu, menurut Nijkamp (2009) menganggap sebuah kota dapat dikatakan cerdas ketika memiliki manajemen sumber daya alam (SDA) yang bijaksana melalui tata pemerintahan yangpartisipatif. Pengelolaan SDA ini untuk akan membentuk suatu konsep dalam pelayanan yang diberikan oleh masyarakat.

Dawes (2008) menyatakan bahwa penggunaan teknologi dalam berbagai kegiatan rutin yang dilaksanakan organisasi publik yaitu menyediakan layanan publik, efektivitas dan efisiensi serta kualitas layanan dasar yang diberikan pemerintah. Penyediaan layanan pemerintah dilakukan untuk memberikan kesejahteraan dan kemudahan bagi masyarakat. Efektivitas dan efisiensi layanan dimaksudkan untuk percepatan pembangunan.

Penggunaan teknologi dalam pelayanan publik dapat memberikan kemudahan bagi masyarakat dalam mengakses kebutuhan yang berkaitan dengan pemerintahan. Hal ini sesuai dengan pendapat Cohen (2012), bahwa kota cerdas merupakan pendekatan terpadu yang luas untuk meningkatkan efisiensi dari operasi kota, kualitas hidup wargakotanya, dan menumbuhkan ekonomi lokal. Selain itu dengan adanya pelayanan yang efisien juga dapat meminimalkan biaya yang tinggi.

Konsep memberikan layanan informasi yang mudah dan cepat bagi masyarakat dengan menggunakan aplikasi teknologi juga dikemukakan oleh Candra Eko (2016) dalam penelitiannya tentang smart city. Dikemukakan bahwa dengan aplikasi teknologi mampu memberikan informasi secara mudah dan cepat sehingga permasalahan dapat diselesaikan dengan cepat serta memberikan kenyamanan, keamanan dan ketertiban.

Berdasarkan beberapa pendapat para ahli tersebut, dapat dimaknai bahwa konsep smart city atau kota cerdas merupakan gambaran layanan publik yang diberikan oleh pemerintah pada masyarakat. Pelayanan ini dapat berupa dalam pelayan kesehatan, keamanan, kenyamanan hidup yang berbasis teknologi. Pelayan publik dalam konsep smart 
city ini akan memberikan efisiensi dan efektifitas dalam pengelolaaannya. Hal ini karena penerapan konsep smart city menggunakan teknologi sebagai dasar dalam setiap pelayanan yang diberikan kepada masyarakat.

\section{B. Smart Mobility}

Smart mobility merupakan salah satu komponen dari smart city.Hal ini sesuai dengan pendapat dari Giffinger(2007) yang menyatakan bahwa terdapat 6 (enam) dimensi dari konsep kota cerdas yaitu 1) smart government (pemerintahan cerdas), 2) Smart Environment (lingkungan cerdas), 3) smart people (masyarakat cerdas), 4) smart economy (ekonomi cerdas), 5) smart living (kehidupan cerdas), dan 6) smart mobility (smart mobility).

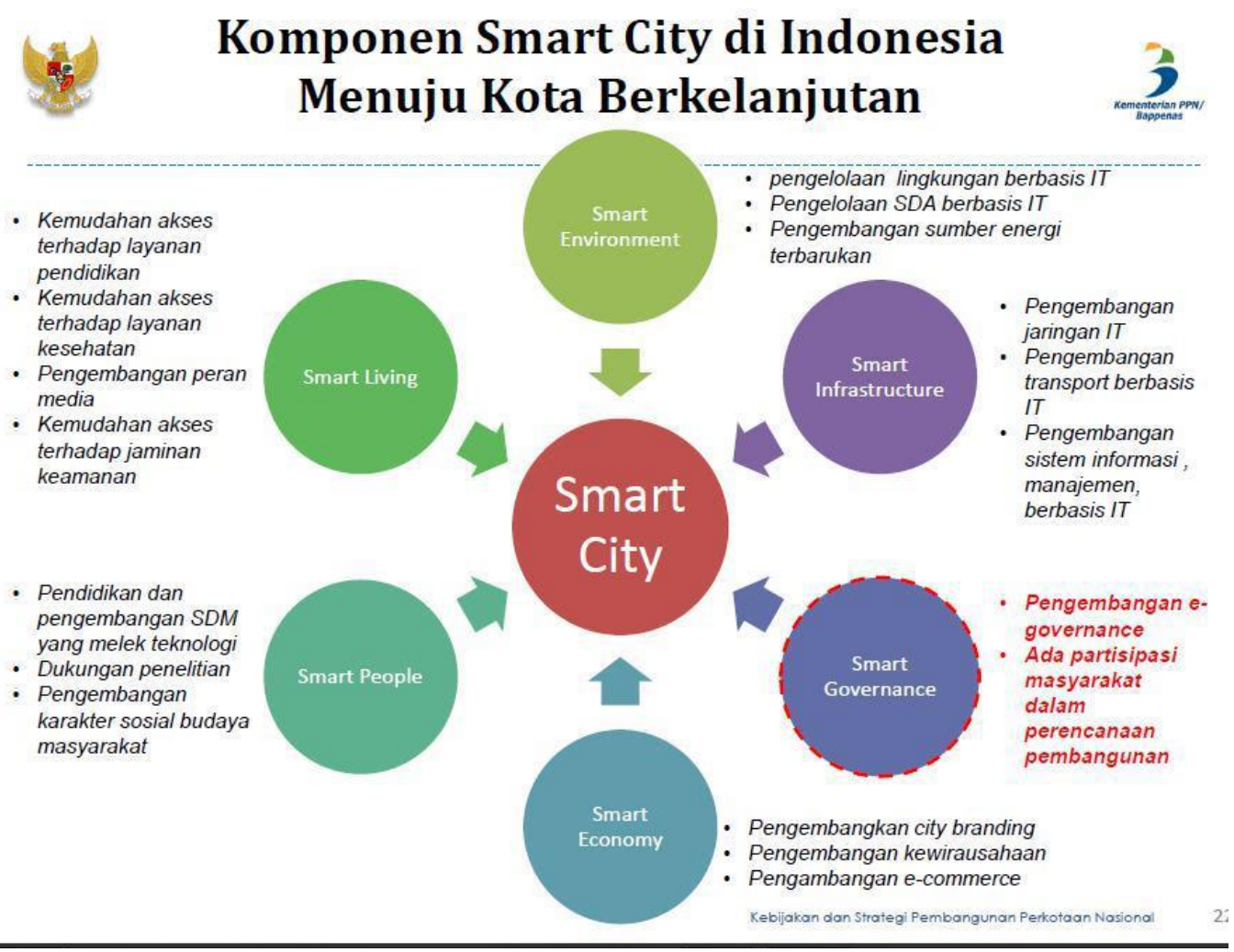

Sumber : Kementrian/Badan Perencanaan Pembangunan Nasional

\section{Gambar 2.1 : Komponen Smart City di Indonesia}

Smart mobility dalam konsep smart city menggambarkan suatu perkembangan lingkungan yang selalu berubah, seperti halnya kemacetan lalu lintas yang semakin lama akan menjadi permasalahan tersendiri bagi kota besar di Indonesia. Hal ini didukung oleh pendapat Boyne (2010) yang menyatakan bahwa untuk menyikapi perubahan lingkungan yang dinamis disektor lalu lintas diperlukan langkah inovasi, sebagai upaya menyikapi permasalahan lalu lintas dengan adanya inovasi yang sesuai dengan kebutuhan konsep smart mobility.

Konsep smart mobility ini tidak dapat terwujud tanpa dukungan dari semua elemen masyarakat, terutama dalam hal kesadaran masyarakat dalam hal pelaksanaan smart mobility, yaitu bagaimana mengatasi permasalahan kemacetan lalu lintas, mengelola sampah, paenanganan banjir dan sebagainya.Oleh karena itu, diperlukan kesadaran masyarakat dalam mewujudkan konsep smart city melalui salah satu komponen berupa smart mobility. 
Enceng dan Hidayat (2016) pada hasil empirisnya menyatakan pencanangan program smart city tidak disertai dengan perencanaan yang matang yang meliputi sumber daya manusia sebagai pelaksanan program, infrastruktur penunjang, dan inovasi dalam layanan publik. Untuk mewujudkan tercapainya konsep smart city perlu ditunjang aspek kepemimpinan serta aspek perencanaan dan sumber daya manusia,

\section{Metodologi Penelitian}

Metode kualitatif menjadi pilihan peneliti pada penelitian ini dengan pendekatan deskriptif yaitu fokus pada pendeskripsian faktor yang menjadi kendala ketercapaian smart city di Kota Tangerang Selatan. Teknik pengumpulan data dengan melakukan pengamatan lapangan, studi dokumen dan wawancara. Sampel sumber data primer digunakan metode purposive sampling yaitu informan yang paham benar konsep smart city terutama implementasi smart mobility, yaitu lbu Dian Anggraeni, S.T., M.Si selaku Kepala Sie Diskominfo, Bapak Heri Darmawan, S.T selaku koordinator pelaksanan, Bapak Asikin, S.T selaku pelaksana, Bapak Herris Yahya selaku Pelaksanan Teknis Bidang Lalu Lintas dan Bapak Abi Irwansah selaku akademisi dan pengguna jalan warga asli Kota Tangerang Selatan. Serta sumber data sekunder meupakan sumber data dokumen yang berhubungan dengan smart city untuk dikaji dan dianalisis yang bersumber dari hasil Konferensie-Indonesia Initiative (ell) dan Smart Indonesia Initiatives (SII) Forum ke-1 di Bandung pada 15 Oktober 2015 dengan topik "Pengembangan Kota Cerdas di Indonesia" dan Laporan Akhir Kajian Penilaian dan Penyusunan Blue Print Kota Tangerang Selatan yang didasarkan pada PP No 96 Tahun 2012 tentang Pelaksanaan Undang-undang No 25 Tahun 2009 tentang Pelayanan Publik.

Peneliti sebagai instrumen peneliti berperan sebagai partisipan pengumpul data. Peneliti menggunakan analisa data secara deskriptif untuk mengeksplorasi fenomena yang menjadi fokus penelitian (Creswell, 2010). Data yang telah dikumpulkan diidentifikasi dan dianalisa secara deskriptif kualitatif sampai dipeeroleh kesimpulan yang menjadi faktor kendala ketercapaian smart city di Kota Tangerang Selatan. Peneliti menggunakan metode triangulasi untuk memverifikasi data.

\section{Hasil Penelitian dan Pembahasan}

\section{A. Kebijakan Smart City Kota Tangerang Selatan}

Bedasarkan arahan dari Walikota Tangerang Selatan, maka arahan pengembangan smart city di Kota Tangerang Selatan ini adalah "Tangerang Selatan Smart City adalah konsep kota yang memanfaatkan teknologi informasi dan komunikasi untuk mengidentifikasi masalah-masalah perkotaan dengan cepat. Dan yang paling penting dari itu semua adalah bagaimana teknologi mampu memperpendek jalur komunikasi antara Pemerintah dan Masyarakat".

Berdasarkan arahan tersebut dan melihat potensi Tangerang Selatan sebagai kota perdagangan dan jasa, maka pengembangan smart city di Tangerang Selatan 
dititik beratkan kepada pemanfaatan teknologi informasi dalam meningkatkan kualitas dan memberikan kemudahan layanan publik kepada masyarakat.

Layanan smart city Kota Tangerang Selatan merupakan konsep sistem yang besar dan komplek, sehingga implementasinya membutuhkan perencanaan yang matang dan realistis dengan mempertimbangkan semua aspek, karena perencanaan yang baik merupakan salah satu faktor penentu kesuksesan penerapan smart city di Kota Tangerang Selatan.

Keberhasilan penerapan konsep smart city di Kota Tangerang Selatan tentu membutuhkan komitmen yang tinggi dari semua elemen masyarakat, yaitu pemerintah, swasta dan masyarakat. Sinergi dari peran ketiga elemen sangat diperlukan artinya, ketiga elemen masyarakat tersebut harus saling mendukung dan selaras dalam mewujudkan cita-cita dan tujuan Kota Tangerang Selatan melalui implementasi smart city yang merupakan proses berkelanjutan dari keenam komponennya.

\section{B. Gambaran Umum Smart City Kota Tangerang Selatan}

Pencanangan smart city di Kota Tangerang Selatan sebagai gagasan untuk memberikan layanan kepada publik dan mengatasi permasalahan secara cepat dan akurat dengan berbasis teknologi informasi (IT) sehingga layanan dapat dilakukan secara online. Berbagai upaya telah dilakukan pemerintahan Kota Tangerang Selatan untuk dapat mengimplementasikan konsep smart city. Contoh, untuk mengurai kemacetan telah dipasang program Area Traffict Control System (ATCS), yaitu program yang secara otomasis mengatur operasional traffict light agar perannnya dapat optimal mengatur lalu lintas. Sistem ini dilengkapi CCTV yang di link an dengan operator Dinas Perhubungan sehingga operator dapat memantau kondisi di lapangan secara otomatis dan dapat segera menangani permasalahan yang terjadi.

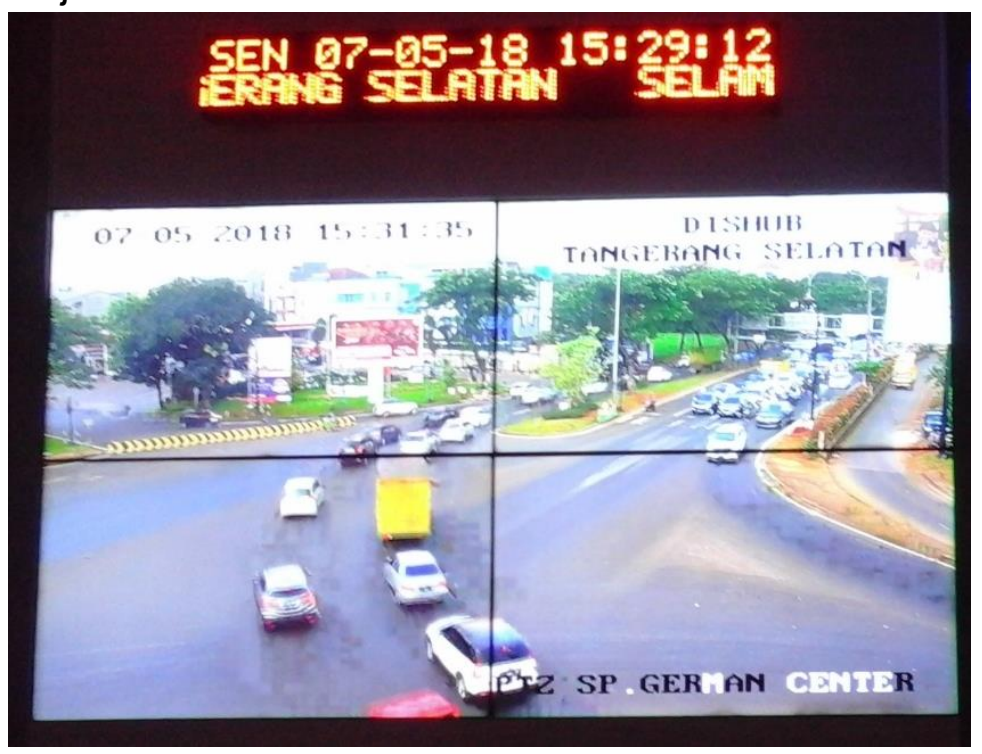




\section{JURNAL ILMIAH ILMU MANAJEMEN}

Berdasarkan hasil penelitian melalui pengamatan, dokumen dan wawancara dengan informan diperoleh hasil bahwa faktor-faktor yang menjadi kendala ketercapaian konsep smart city meliputi aspek:

\section{Peraturan Daerah}

a. Belum keluarnya Peraturan Daerah yang menjadi payung induk program smart city meskipun konsep smart city di Kota Tangerang Selatan sudah dicanangkan pada tahun 2016;

b. Adanya pergantian pemimpin yang berdampak pada regulasi sehingga juga berdampak pada pengambilan kebijakan. Contoh, sebelumnya sudah akan dibentuk Dewan Pelaksana smart city, karena Peraturan Walikota belum keluar dan adanya pergantian Kepala Bidang Diskominfo maka pembentukan Dewan Pelaksanan smart city belum jadi dibentuk.

\section{Sumber Daya Manusia}

a. Minimnya SDM yang latar belakang pendidikannya berbasis IT;

b. Kurangnya personil yang standby di kantor karena pada jam efektif, terutama jam 7.00 WIB $80 \%$ pegawai Dinas Perhubungan Kota Tangerang Selatan turun di jalan untuk membantu menertibkan lalu lintas;

c. Kurangnya koordinasi antar Unit Pelaksana Teknik (UPT).

\section{Anggaran}

a. Jika ada permasalahan di lapangan, penanganan masalah cenderung lama karena proses birokrasi. Contoh apabila salah satu sistem ATCS mati maka untuk segera menangani tidak bisa karena harus diajukan anggaran dulu dan hal itu butuh waktu.

b. Berlakunya sistem sentralisasi, maka segala jalur anggaran tersentral/terpusat;

c. Adanya kewenangan daerah, artinya kalau jalan itu merupakan jalur propinsi maka pada saat terjadi kerusakan jalan, maka hal ini menjadi kewenangan pemerintah propinsi untuk mengatasi masalah tersebut. Contoh, pada saat jalan Siliwangi Pamulang rusak karena erosi maka pemerintah Kota Tangerang Selatan tidak bisa mengambil tindakan karena Jl. Siliwangi Pamulang merupakan kewenangan wilayah Propinsi Banten.

\section{Kesadaran Masyarakat Kota Tangerang Selatan.}

a. Masyarakat masih belum sepenuhnya menyadari pentingnya keselamatan diri dan orang lain;

b. Masyarakat Kota Tangerang Selatan belum memiliki budaya tertib lalu lintas;

c. Kepemilikan kendaraan belum terkendali, artinya belum bisa diterapkan aturan yang menegaskan bahwa satu keluarga satu kendaraan sehingga volume kendaraan di jalan terus meningkat.

d. Kurang gencarnya sosialisasi dari pemerintah atas dicanangkannya konsep smart city untuk Kota Tangerang selatan sehingga masyarakat banyak yang masih awam tentang konsep smart city.

Setelah dilakukan analisa data dari hasil turun lapang baik yang bersumber dari data dokumen, pengamatan dan wawancara, kesimpulan sementara bahwa banyak faktor yang menjadi kendala untuk ketercapaian konsep smart city di Kota Tangerang Selatan. Artinya, untuk dapat menjadi konsep smart city di Kota Tangerang Selatan pelu sinergisitas dari berbagai elemen masyarakan dan bertekat untuk mewujudkan Kota Tangerang Selatan sebagai kota cerdas tidak hanya merupakan wacana atau sekedar sudah dicanangkan 
melainkan telah menjadi komitmen masyarakat bersama pemerintah mewujudkan Kota Tangerang Selatan menjadi kota cerdas.

Program yang baik adalah program yang siap dijalankan dengan konsep yang matang dan memiliki dasar hukum yang kuat untuk menjalakannya seperti Peraturan Daerah agar arah dan tujuannya jelas. Dan harus ditunjang oleh sumber daya manusia yang ahli dibidangnya serta sarana prasarana yang memadai. Karena tujuan dari konsep smart city adalah memberilakn layanan publik yang cepat, tepat, efektif dan efisien, maka penting untuk mensosialisasikan program kepada masyarakat agar mengerti dan mendukung tercapainya tujuan dari program tersebut. Contoh, implementasi sistem ATCS yang secara otomatis mengatur traffict light sesuai tingkat volume kendaraan yang berada dia area traffict light perlu disosialisasikan agar masyarakat dapat tertib berlalu lintas.

Program dengan konsep dan perencanaan smart city yang matang serta persiapan pelaksanaan program yang memadai akan meminimalkan kendala ketercapaian konsep smart city di Kota Tangerang Selatan yang berkelanjutan (sustainable). Tentu saja semua elemen smart city harus berjalan seiring bersama, tidak bisa hanya smart mobility tetapi kelima elemen lainnya yang meliputi: smart people, smart environment, smart economic, smart living, dan smart goverment juga bersinergi mewujudkan kota cerdas.

Smart mobility yang merupakan bagian dari konsep program smart city di Kota Tangerang Selatan meskipun sudah diimplementasikan aplikasi ATCS di beberapa traffict light dengan tujuan untuk memberikan kualitas layanan kepada masyarakat terkait transportasi masih belum optimal ketercapaiannya terbukti masih banyak terjadi kemacetan di beberapa titik jalan karena memang baru terpasang empat CCTV dan ini masih jauh dari cukup, perlu dilakukan penambahan CCTV program smart mobility dapat optimal.

\section{Kesimpulan dan Saran}

A. Kesimpulan

Berdasarkan hasil analisa data yang diperoleh dari turun lapang maka peneliti dapat menarik kesimpulan bahwa faktor-faktor kendala ketercapaian smart mobility Dalam Upaya Menuju Konsep Smart City di Kota Tangerang Selatan antara lain aspek:

\section{Peraturan Pemerintah Daerah}

Yaitu belum keluarnya Peraturan Pemerintah yang menjadi payung induk program smart city sehingga pelaksanaannya belum optimal.

\section{Sumber Daya Manusia}

Yaitu mininnya jumlah sumber daya manusia yang latar belakang pendidikannya berbasis IT, sehingga siap menjalankan program smart city;

\section{Anggaran}

Dalam hal ini anggaran yang sifatnya sentralisasi dan terkait birokrasi sehingga membutuhkan waktu untuk merealisasikan anggaran sementara permasalahan di lapangan membutuhkan penanganan yang cepat.

\section{Kesadaran Masyarakat}

Kesadaran masyarakan mempunyai peran yang sangat besar dalam mewujudkan ketercapaian smart mobility menuju konsep smart city, karena program ini diperuntukkan masyarakat sehingga masyarakat harus mendukung ketercapaian program smart city secara optimal.

\section{B. Saran}




\section{JURNAL ILMIAH ILMU MANAJEMEN}

1. Pemerintah dalam meluncurkan program perlu dikonsep dan direncanakan secara matang yang berdasarkan hukum serta menyiapkan sumber daya manusianya sehingga pelaksanaan program dapat berjalan secara efelktif dan efisien dengan hasil yang maksimal.

2. Kebijakan pemerintah sudah tentu bertujuan untuk menyejahterakan masyarakat, untuk itu perlu timbal balik dan peran aktif masyarakat dalam mensukseskan program pemerintah.

3. Perlu sinergisitas semua elemen masyarakat untuk mencapai tujuan setiap program pemerintah secara optimal untuk pencapaian tujuan.

\section{DAFTAR PUSTAKA}

Boyne, G., Asworth R., and Tom E. 2010. Public Service Improvement: Theories and Evidence. New York: Oxford Universty Press

Chandra Eko, 2016. Strategi Pembangunan Smart City dan tantangannya Bagi Masyarakat Kota. Jurnal Strategi dan Bisnis Vol.4 No.2, 2016.

Cohen, B. "The Top 10 Smart Cities on The Planet". Fast Company, 11 Januari 2012.

Dawes, S.S. 2008. The Evolution and ContinuingChallenges of E-Governance. PublicAdministration Review. Vol. 68. pp.86-102.

Enceng dan Hidayat, 2016. Peningkatan Layanan Publik Melalui Smart Governance Dan Smart Mobility. Jurnal Administrasi Pembangunan, Volume 4, Nomor 2, Maret 2016, hlm. 87-156.

Giffinger, R., Fertner, C., \& Kramar, H. 2007. "City Ranking of European Medium SizedCities". Vienna University of Technology \& Delft University of Technology

Laporan Akhir Kajian Penilaian dan Penyusunan Blue Print Kota Tangerang Selatan, 2016. PT Multimedia Solusi Prima.

Mujiyono, dkk. Kesiapan Kota Pekalongan Menuju Smart City. Jurnal Litbang Kota Pekalongan Vol. 11 Tahun 2016

Nurmandi, A. 2006. Manajemen Perkotaan: Aktor, Organisasi, Pengelolaan Daerah Perkotaan dan Metropolitan di Indonesia. Yogyakarta: Sinergi Publishing.

PP No 96 Tahun 2012 tentang Pelaksanaan Undang-undang No 25 Tahun 2009 tentang Pelayanan Publik.

Sabrina. 2016. Metode Penelitian dan Pengembangan (Research and Development) Untuk Bidang: Pendidikan, Managemen, Sosial, dan Teknik. Bandung: Alfabeta.

Sanusi Anwar, 2011. Metodologi Penelitian Bisnis, Disertai contoh Proposal Penelitian Bidang IImu Ekonomi dan Manajemen. Jakarta: Salemba Empat.

Sugiyono. 2012. Metode Penelitian Pendidikan: Pendekatan Kuantitatif, Kualitatif, dan R\&D. Bandung: Alfabeta.

Wartakota Tribunnews, 1 September 2016. Jumlah Kendaraan di Kota Tangerang Selatan. Di akses 19 Sepetember 2018.

Wahyudi dan Hariadi, 2016. Strategi Pembangunan Smart City dan tantangannya bagi Masyarakat Kota. Jurnal Strategi dan Bisnis Vol.4, No. 2 | Oktober 2016. 